\title{
Benzo(a)pyrene induces similar gene expression changes in testis of DNA repair proficient and deficient mice
}

\author{
Nicole Verhofstad', Jeroen LA Pennings'2, Conny ThM van Oostrom², Jan van Benthem², Frederik J van Schooten', \\ Harry van Steeg ${ }^{2}$ and Roger WL Godschalk*1
}

\begin{abstract}
Background: Benzo [a]pyrene (B[a]P) exposure induces DNA adducts at all stages of spermatogenesis and in testis,

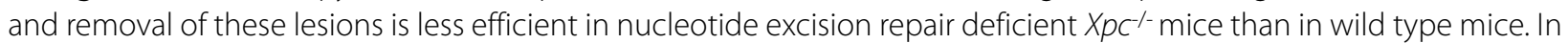
this study, we investigated by using microarray technology whether compromised DNA repair in Xpc/-mice may lead to a transcriptional reaction of the testis to cope with increased levels of B[a]P induced DNA damage.

Results: Two-Way ANOVA revealed only 4 genes differentially expressed between wild type and $\mathrm{Xpc}^{-1-m i c e}$, and 984 genes between testes of $B[a] P$ treated and untreated mice irrespective of the mouse genotype. However, the level in which these B[a]P regulated genes are expressed differs between Wt and $X p c^{-1-}$ mice $(p=0.000000141)$, and were predominantly involved in the regulation of cell cycle, translation, chromatin structure and spermatogenesis, indicating a general stress response. In addition, analysis of cell cycle phase dependent gene expression revealed that expression of genes involved in G1-S and G2-M phase arrest was increased after B[a]P exposure in both genotypes. A slightly

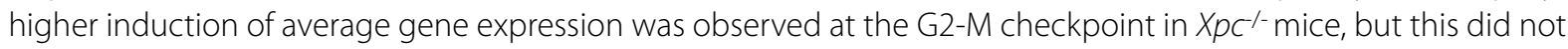
reach statistical significance $(P=0.086)$. Other processes that were expected to have changed by exposure, like apoptosis and DNA repair, were not found to be modulated at the level of gene expression.

Conclusion: Gene expression in testis of untreated $\mathrm{Xpc}^{-/}$and wild type mice were very similar, with only 4 genes differentially expressed. Exposure to benzo(a)pyrene affected the expression of genes that are involved in cell cycle regulation in both genotypes, indicating that the presence of unrepaired DNA damage in testis blocks cell proliferation to protect DNA integrity in both DNA repair proficient and deficient animals.
\end{abstract}

\section{Background}

Exposure to chemicals like benzo(a)pyrene (B[a]P) can lead to structural changes in DNA and as a consequence to the development of diseases with a genetic basis [1]. Changes in the DNA sequence can be induced by exposure to chemicals during life, but may also be inherited via mutations in the spermatogonial stem cells; in that way increasing the risk of developing abnormalities or diseases in the offspring $[2,3]$. The mutagenic potential of $\mathrm{B}[\mathrm{a}] \mathrm{P}$ in male germ cells, however, has still not been fully established. B[a]P related DNA damage was observed at

*Correspondence: r.godschalk@grat.unimaas.nl

1 Department of Health Risk Analysis and Toxicology, School for Nutrition, Toxicology and Metabolism, Maastricht University, PO box 616, 6200 MD Maastricht, the Netherlands

Full list of author information is available at the end of the article all stages of spermatogenesis and in testis [4,5], but it is largely unknown how germ cells deal with DNA damage to protect their genetic material, and to prevent the accumulation of mutations in the germ line.

Spermatogenesis is carefully controlled to produce mature spermatozoa from spermatogonial stem cells in three major stages; the mitotic stage, the meiotic stage and the maturation stage. Germ cells are susceptible for the induction of mutations during mitotic and meiotic divisions, because cell turnover is a prerequisite for fixation of DNA damage into mutations. However, it is likely that several processes prevent the occurrence of gene mutations in male germ cells; for example, DNA damage can be removed by DNA repair mechanisms, of which nucleotide excision repair (NER) is considered to be the 
most relevant repair mechanism for bulky DNA adducts formed by reactive metabolites of $\mathrm{B}[\mathrm{a}] \mathrm{P}$. Two NER mechanisms have been described: global genome repair (GGR) eliminates bulky DNA lesions in the entire genome, whereas transcription coupled repair (TCR) specifically removes lesions that block RNA synthesis [6]. In a previous study, we observed that GGR/NER plays an important role in the removal of $\mathrm{B}[\mathrm{a}] \mathrm{P}$ induced DNA adducts in the testis, especially in the first week after exposure [5]. $\mathrm{B}[\mathrm{a}] \mathrm{P}$ induced DNA adduct levels in the testis were significantly different between Wt and $X_{p c^{-/}}$mice, especially at 4 days after a single exposure to B[a]P (0.69 \pm 0.16 and $1.84 \pm 0.70$ adducts per $10^{8}$ nucleotides in $\mathrm{Wt}$ and $\mathrm{Xpc}^{-/-}$mice, respectively). Therefore, in an attempt to reveal the responses in the testis to this damage, we investigated by using microarrays the changes in gene expression induced by $\mathrm{B}[\mathrm{a}] \mathrm{P}$ in testis from $\mathrm{Wt}$ and $\mathrm{Xpc}^{-1-}$ male mice, 4 days after exposure to $\mathrm{B}[\mathrm{a}] \mathrm{P}$. Since $\mathrm{Xpc}^{-/-}$mice lack one of the most important protective mechanisms against $\mathrm{B}[\mathrm{a}] \mathrm{P}$ induced DNA damage, we expected a different (adaptive) transcriptional response in these mice as compared to their Wt counterparts.

\section{Results}

\section{Gene expression profiling}

Two-way ANOVA revealed 984 regulated genes that were differentially expressed between treated and untreated mice (FDR 5\%), of which 638 genes were increased and 346 genes were decreased by $\mathrm{B}[\mathrm{a}] \mathrm{P}$ exposure. Only 4 genes (Xpc, Cml2, D6Mm5e and 2610209M04Rik) were differentially expressed between unexposed Wt and unexposed $\mathrm{Xpc}^{-/-}$mice (FDR 5\%), and they are all located at the same site of chromosome 6. Of these 4 genes, $X p c$, $\mathrm{Cml} 2$ and $\mathrm{D} 6 \mathrm{Mm} 5 \mathrm{e}$ were decreased in expression in $\mathrm{Xpc}^{-1}$ - mice as compared to the Wt mice, with higher gene expression levels of $C m l 2$ and $D 6 M m 5 e$ than the very low levels of Xpc. On the other hand, 2610209M04Rik was increased in $X p c^{-/-}$mice. This confirms the absence of a functional $X p c$ gene in the $X p c^{-/-}$genotype, and shows that closely linked genes have significantly altered expression patterns. Finally, our results show that there is only a modest difference between the gene expression patterns in testis of $\mathrm{B}[\mathrm{a}] \mathrm{P}$ treated $\mathrm{Wt}$ and $X p \mathrm{c}^{-/-}$mice. Nonetheless, a paired T-test showed that the level in which these $B[a] P$ regulated genes are expressed differs between $\mathrm{Wt}$ and $X p c^{-1-}$ mice $(\mathrm{p}=0.000000141)$. The clustering of the combined hits is presented in Figure 1.

\section{Analysis of pathway regulation}

The list of the 638 genes that were induced by B[a]P suggested, by using DAVID/EASE, a significant enrichment for several Gene Ontology (GO) biological processes and Swiss-Prot_Protein Information Resource (SP_PIR) terms, such as 'cell division' $(p=0.000000082)$, 'mitosis' ( $p$

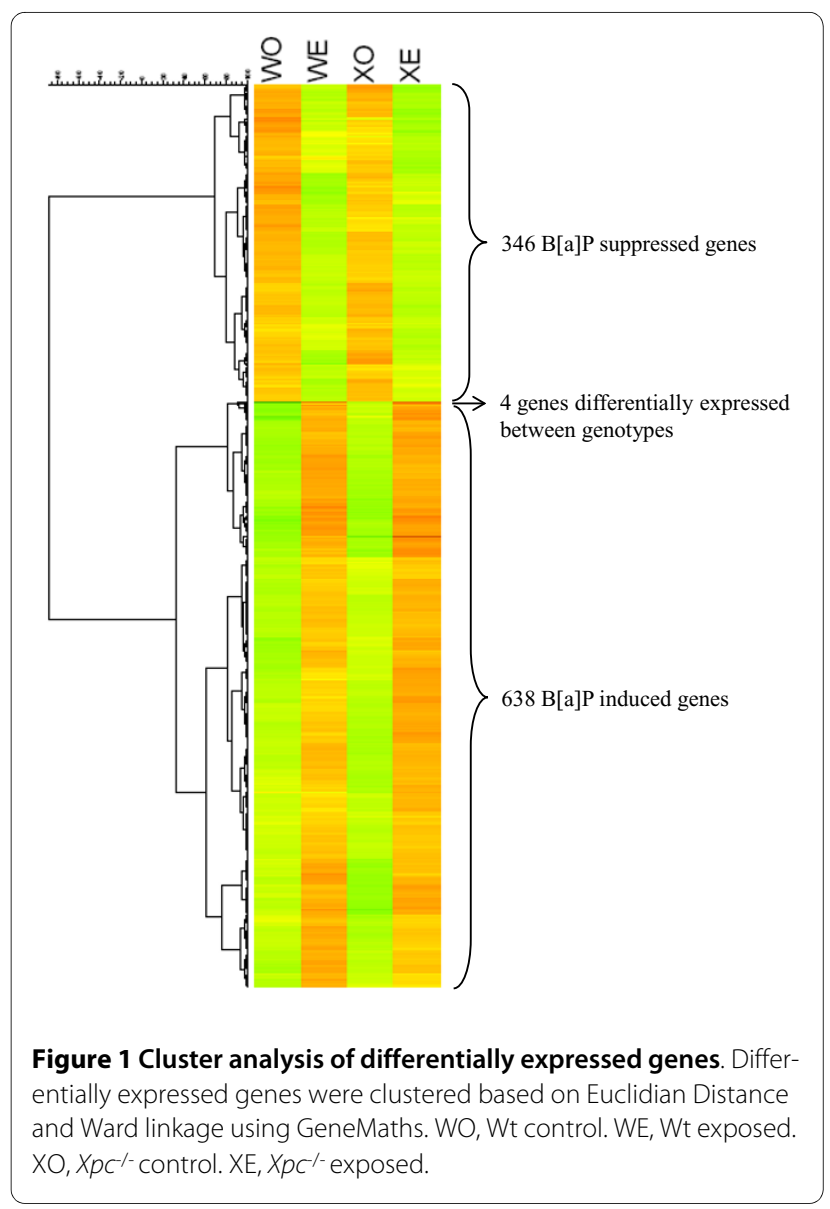

$=0.00000037)$, 'chromosome segregation' $(\mathrm{p}=0.000085)$ and 'spermatogenesis' ( $\mathrm{p}=0.00024)$ (Additional file 1). The 346 genes that were down regulated by $\mathrm{B}[\mathrm{a}] \mathrm{P}$ exposure also showed an enrichment for several pathways, including 'oxidative phosphorylation' ( $\mathrm{p}=0.0011$ ) (Additional file 2). In addition, two GO terms for the cellular components mitochondrial part $(\mathrm{p}=0.001)$ and mitochondrion ( $\mathrm{p}=0.0011)$, were enriched among $\mathrm{B}[\mathrm{a}] \mathrm{P}$ suppressed genes, which is in line with the inhibition of the oxidative phosphorylation process.

The combined list of $\mathrm{B}[\mathrm{a}] \mathrm{P}$ (both up and down) regulated genes showed an enrichment of 110 GO and SP_PIR terms (Additional file 3), including cell cycle, translation, chromatin structure and spermatogenesis, which we already found to be enriched among the up regulated genes only. Therefore, we used these 4 processes to further select genes and to subsequently compare the two genotypes regarding their gene expression ratios between $\mathrm{B}[\mathrm{a}] \mathrm{P}$ treated $v s$. control groups. An overview of the gene expression ratio distribution is given in Table 1.46 differentially regulated genes were involved in the cell cycle (Table 2), of which 20 genes were induced to a higher extent in $\mathrm{Xpc}^{-/-}$mice, whereas only 12 of these genes were expressed to a higher extent in Wt mice. Regarding the 
Table 1: Comparison of gene expression ratios.

\begin{tabular}{lccccc}
\hline Pathway & Total \# genes & Uw & Ux & Dw & Dx \\
\hline Cell cycle & 46 & 12 & 20 & 8 & 6 \\
$\begin{array}{l}\text { Chromatin } \\
\text { structure }\end{array}$ & 37 & 8 & 20 & 8 & 1 \\
Translation & 59 & 18 & 22 & 7 & 12 \\
Spermatogenesis & 32 & 10 & 12 & 9 & 1 \\
\hline
\end{tabular}

Average gene expression ratios for genes involved in significantly regulated pathways are compared between $\mathrm{Wt}$ and $\mathrm{Xpc}^{1-}$-mice. The table shows the number of genes that are up or down regulated to a higher extent after B[a]P exposure in either genotype.

Uw, up regulated to a higher extent in Wt mice. Ux, up regulated to a higher extent in $\mathrm{Xpc}^{-/}$mice. Dw, down regulated to a greater extent in Wt mice. Dx, down regulated to a greater extent in $\mathrm{Xpc}^{/-}$mice.

genes that were inhibited in their expression, 6 genes were more suppressed in $\mathrm{Xpc}^{-/-}$mice, and 8 genes in $\mathrm{Wt}$ mice as compared to animals of the other genotype. In addition, we found 37 genes that are involved in the chromatin structure (Additional file 4), of which 20 genes were more induced in $\mathrm{Xpc}^{-1-}$ mice, and 8 genes in Wt mice. Only 8 chromatin structure related genes were more suppressed in Wt mice, as compared to 1 gene in $\mathrm{Xpc}^{-1-}$ mice. Among the spermatogenesis related genes (Additional file 5), we only found differences between Wt and $\mathrm{Xpc}^{-1-}$ animals among the $\mathrm{B}[\mathrm{a}] \mathrm{P}$ suppressed genes; 9 genes were more suppressed in Wt mice compared to 1 gene in $\mathrm{Xpc}^{-/-}$mice as compared to animals of the other genotype. Taken together, these results indicate that gene expression differences between $\mathrm{Wt}$ and $\mathrm{Xpc}^{-1-}$ mice are small, and that the induction of genes involved in cell division regulating processes was stronger in $\mathrm{Xpc}^{-1-}$ than in Wt mice. We did not find relevant differences in average gene expression ratios between $\mathrm{Xpc}^{-/}$and Wt mice among translation related genes, that are given in Additional file 6 .

Among the $110 \mathrm{GO}$ and SP_PIR terms that were obtained from the combined list of $\mathrm{B}[\mathrm{a}] \mathrm{P}$ (both up and down) regulated genes, we again found a few mitochondria related terms, such as the cellular components 'mitochondrial part', 'mitochondrial envelope' and 'mitochondrial membrane', and the SP_PIR Keyword 'mitochondrion'. Furthermore, we found the SP_PIR keyword 'chaperone', which involves genes that are known to be activated during a stress response.

\section{Cell cycle phase activity}

The setwise average gene expression levels of cell cycle related gene sets were calculated for sets of genes related to specific cell cycle phases, in order to study cell cycle phase activity (Figure 2). The sets used were based on GO functional annotation for the complete cell cycle or genes found specifically expressed in a particular cell cycle phase, reported by both Bar-Joseph et al. [7] and Whitfield et al. [8]. Average gene expression levels of all cell cycle genes were lower in $\mathrm{Xpc}^{-/-}$mice than in Wt mice ( $\mathrm{p}$ $=0.024)$ in the absence of exposure to $\mathrm{B}[\mathrm{a}] \mathrm{P}$. However, after $\mathrm{B}[\mathrm{a}] \mathrm{P}$ exposure gene expression levels of the same cell cycle related genes were increased to comparable levels in both genotypes. When focusing on specific cell cycle phases, we observed that the average gene expression levels of genes within the cell cycle transition between $\mathrm{G} 1$ and $\mathrm{S}$ was similar in Wt and $\mathrm{Xpc}^{-/-}$control mice, and again increased after $\mathrm{B}[\mathrm{a}] \mathrm{P}$ exposure to equal levels $(p=0.937)$. On the other hand, the average level of expression of genes involved in the G2-M phase transi-

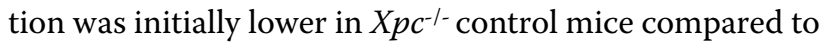
the Wt control mice, and gene expression levels were increased by $\mathrm{B}[\mathrm{a}] \mathrm{P}$ exposure to a higher extent in $\mathrm{Xpc}^{-1}$ mice compared to the Wt mice. Table 3 shows the gene expression ratios of the 18 genes involved in the G2-M phase transition, indicating that 11 out of these 18 genes were more induced in $\mathrm{Xpc}^{-1}$ mice after B[a]P exposure as compared to Wt mice $(\mathrm{p}=0.086)$. Although these differences between Wt and $\mathrm{Xpc}^{-/-}$mice are not significant, they are consistent since the majority of genes respond into the same direction, and represent an observed trend towards a more pronounced response to B[a]P in $\mathrm{Xpc}^{-1-}$ mice. Within the M-G1 phase, we observed a low impact of $\mathrm{B}[\mathrm{a}] \mathrm{P}$ exposure in both genotypes, as compared to the other cell cycle phases. Also within this cell cycle phase, the response to $\mathrm{B}[\mathrm{a}] \mathrm{P}$ was more pronounced in $\mathrm{Xpc}^{-/-}$ mice than in Wt mice, although this was based on the expression of 4 genes only $(\mathrm{p}=0.300)$.

\section{Validation with quantitative Real-Time PCR}

Quantitative Real-Time PCR (qPCR) was performed on 4 selected genes that are involved in the G2-M phase transition to validate the gene expression changes in Wt $v s$. $X p c^{-/-}$mice after B[a]P exposure. Three genes (Cit, Ect2 and Psip1) were selected because their average gene expression ratios were most different between $\mathrm{Wt}$ and

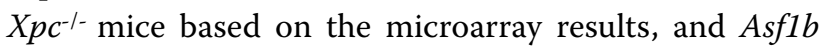
was selected as a control because of the small difference between Wt and $\mathrm{Xpc}^{-/}$mice. After gene expression 
Table 2: Differentially regulated genes regarding the cell cycle process after B[a]P exposure.

\begin{tabular}{|c|c|c|c|}
\hline Symbol & Gene Name & Wt & Xpc-I- \\
\hline Bin3 & bridging integrator 3 & 1.13 & 1.31 \\
\hline Brca2 & breast cancer 2 & -1.35 & -1.34 \\
\hline Brms1 & breast cancer metastasis-suppressor 1 & -1.18 & -1.34 \\
\hline Calr & calreticulin & -1.26 & -1.31 \\
\hline Ccnb2 & cyclin B2 & -1.24 & -1.16 \\
\hline Ccng2 & cyclin G2 & 1.23 & 1.32 \\
\hline Conk & cyclin $\mathrm{K}$ & 1.21 & 1.23 \\
\hline Cdc $25 c$ & cell division cycle 25 homolog C (S. cerevisiae) & -1.09 & -1.30 \\
\hline $\mathrm{Cdc} 27$ & cell division cycle 27 homolog (S. cerevisiae) & 1.41 & 1.31 \\
\hline $\mathrm{Cdc} 42$ & cell division cycle 42 homolog (S. cerevisiae) & 1.34 & 1.50 \\
\hline Cdca1 & cell division cycle associated 1 & 1.24 & 1.50 \\
\hline Cdca5 & cell division cycle associated 5 & 1.18 & 1.30 \\
\hline Cdca8 & cell division cycle associated 8 & -1.24 & -1.11 \\
\hline Cdk5rap3 & CDK5 regulatory subunit associated protein 3 & -1.24 & -1.23 \\
\hline Cetn 1 & centrin 1 & 1.46 & 1.31 \\
\hline Cit & citron & 1.20 & 1.35 \\
\hline Cks2 & CDC28 protein kinase regulatory subunit 2 & 1.29 & 1.36 \\
\hline Cul3 & cullin 3 & 1.28 & 1.18 \\
\hline Dhcr24 & 24-dehydrocholesterol reductase & 1.50 & 1.43 \\
\hline Dnajc2 & DnaJ (Hsp40) homolog, subfamily $C$, member 2 & -1.42 & -1.23 \\
\hline Fzr1 & fizzy/cell division cycle 20 related 1 (Drosophila) & 1.44 & 1.39 \\
\hline Gspt1 & G1 to $S$ phase transition 1 & 1.37 & 1.31 \\
\hline Hells & helicase, lymphoid specific & 1.43 & 1.46 \\
\hline Incenp & inner centromere protein & 1.17 & 1.29 \\
\hline Kif20a & kinesin family member $20 \mathrm{~A}$ & 1.54 & 1.41 \\
\hline Macf1 & microtubule-actin crosslinking factor 1 & 1.16 & 1.49 \\
\hline Mad2l2 & MAD2 mitotic arrest deficient-like 2 (yeast) & 1.19 & 1.27 \\
\hline Mphosph6 & M phase phosphoprotein 6 & 1.30 & 1.26 \\
\hline Mtus1 & mitochondrial tumor suppressor 1 & -1.22 & -1.19 \\
\hline Nasp & $\begin{array}{l}\text { nuclear autoantigenic sperm protein (histone- } \\
\text { binding) }\end{array}$ & 1.34 & 1.38 \\
\hline Nek4 & $\begin{array}{l}\text { NIMA (never in mitosis gene a)-related expressed } \\
\text { kinase } 4\end{array}$ & 1.31 & 1.37 \\
\hline Pin 1 & $\begin{array}{l}\text { protein (peptidyl-prolyl cis/trans isomerase) NIMA- } \\
\text { interacting } 1\end{array}$ & 1.31 & 1.26 \\
\hline Рpp3ca & $\begin{array}{l}\text { protein phosphatase } 3 \text {, catalytic subunit, alpha } \\
\text { isoform }\end{array}$ & -1.19 & -1.22 \\
\hline Pten & phosphatase and tensin homolog & 1.32 & 1.31 \\
\hline Rad17 & RAD17 homolog (S. pombe) & 1.22 & 1.27 \\
\hline Ranbp1 & RAN binding protein 1 & -1.24 & -1.23 \\
\hline Rbm5 & RNA binding motif protein 5 & 1.34 & 1.39 \\
\hline Sgol1 & shugoshin-like 1 (S. pombe) & 1.26 & 1.20 \\
\hline
\end{tabular}


Table 2: Differentially regulated genes regarding the cell cycle process after B[a]P exposure. (Continued)

\begin{tabular}{|c|c|c|c|}
\hline Smarcb1 & $\begin{array}{l}\text { SWI/SNF related, matrix associated, actin } \\
\text { dependent regulator of chromatin, subfamily } b \text {, } \\
\text { member } 1\end{array}$ & 1.27 & 1.33 \\
\hline Sycp3 & synaptonemal complex protein 3 & 1.34 & 1.30 \\
\hline Tacc3 & transforming, acidic coiled-coil containing protein 3 & 1.31 & 1.34 \\
\hline Tipin & timeless interacting protein & -1.22 & -1.24 \\
\hline Trrap & $\begin{array}{l}\text { transformation/transcription domain-associated } \\
\text { protein }\end{array}$ & -1.26 & -1.22 \\
\hline Tubb6 & tubulin, beta 6 & -1.33 & -1.44 \\
\hline Ube2i & ubiquitin-conjugating enzyme E2I & 1.17 & 1.30 \\
\hline Zw10 & $\begin{array}{l}\text { ZW10 homolog (Drosophila), centromere/ } \\
\text { kinetochore protein }\end{array}$ & 1.23 & 1.30 \\
\hline
\end{tabular}

changes were normalised to the Hprt1 reference, qPCR data of the 3 strongly differentially expressed genes indeed showed a higher induction of gene expression after $\mathrm{B}[\mathrm{a}] \mathrm{P}$ exposure in $X p c^{-/-}$mice (ratios are $1.15 \mathrm{vs}$. 1.18, 1.00 vs. 1.05 and 1.00 vs. 1.04 for Cit, Ect2 and Psip1, in Wt and $X p c^{-/-}$mice, respectively). However, the effect of $\mathrm{B}[\mathrm{a}] \mathrm{P}$ exposure was smaller on basis of the qPCR expression data. QPCR data of $A s f 1 b$ showed a down regulation after $\mathrm{B}[\mathrm{a}] \mathrm{P}$ exposure in both $\mathrm{Wt}$ and $\mathrm{Xpc}^{-/-}$mice (ratios are 0.94 and 0.98 , respectively), and did therefore, not confirm the microarray results. Overall, 3 out of 4 selected genes confirmed the microarray results found within the G2-M phase, showing that $\mathrm{B}[\mathrm{a}] \mathrm{P}$ induces marginally higher gene expression changes in $\mathrm{Xpc}^{-/-}$than in Wt mice.

\section{Discussion}

$\mathrm{B}$ [a]P exposure leads to the formation of DNA adducts in testis and sperm of exposed male mice and humans $[4,5]$. These pro-mutagenic DNA adducts are usually removed by DNA repair mechanisms to prevent the accumulation of mutations. In a previous study, we found that there is a difference in DNA adduct removal between Wtand $\mathrm{Xpc}^{-/-}$ mouse testes [5]. In the first week after exposure to $\mathrm{B}[\mathrm{a}] \mathrm{P}$, we observed more DNA adducts in testis of $\mathrm{Xpc}^{-/-}$mice, and a slower decline of DNA adducts over time. In addition, we showed that spermatogonial stem cells rely on nucleotide excision repair for the complete removal of DNA adducts during spermatogenesis [5]. This suggests that GGR/NER plays an important role in mice in protecting the testis and sperm cells from DNA damage by $\mathrm{B}[\mathrm{a}] \mathrm{P}$. In the present study, we used a microarray approach to study whether these differences in DNA adduct removal between Wt and $\mathrm{Xpc}^{-/-}$mice are accompanied by differences in gene expression, thereby elucidating adaptive responses towards the induction of heritable DNA damage in testis. We chose to analyze gene expression after 4 days, since at that time point DNA adduct levels differed more between Wt and $\mathrm{Xpc}^{-/}$ mice compared to Day 1 , and still differed at Day 7 [5].

Two-Way ANOVA indicated that there are only minor expression differences between $X_{p c^{-/-}}$and Wt mice. No more than 4 genes $(X p c, C m l 2, D 6 M m 5 e$ and 2610209M04Rik) located in a $10 \mathrm{MB}$ locus on chromosome 6, were differentially expressed between the two genotypes. Although the expression levels of $\mathrm{Cml2}$, $D 6 M m 5 e$ and 2610209M04Rik were higher as compared to the very low levels of $X p c$, the fact that these genes are located in proximity to the $X p c$ gene on chromosome 6 suggests that mutating the $X p c$ gene has changed the genomic or regulatory structure at that particular site and therefore the expression of these 3 genes. Another explanation could be that these 3 genes are of an Ola129 genetic background, which is used to create the $X p c$ mutant, and are for some unknown reason differently expressed [9].

The main differences were found between the $B[a] P$ exposed and control mice, regardless of genotype. 984 Genes were differentially regulated after $\mathrm{B}[\mathrm{a}] \mathrm{P}$ exposure and these were enriched for genes involved in cell cycle, translation (ribosomes), chromatin structure and spermatogenesis. Besides these pathways, other more general processes were found to be affected (Additional file 3). Regulated processes regarding mitochondrial function (energy metabolism), chaperones, and the aforementioned changes in cell cycle seem to indicate a general stress response after exposure to $\mathrm{B}[\mathrm{a}] \mathrm{P}$ in testes of both genotypes. In addition, the altered expression of mitochondria related genes is indicative for changes in the oxidative phosphorylation; this process was also found to be affected among the $\mathrm{B}[\mathrm{a}] \mathrm{P}$ down regulated genes, and the genes for several ATP synthase subunits, NADH 
Table 3: Differentially regulated genes involved in G2-M phase transition.

\begin{tabular}{|c|c|c|c|}
\hline Symbol & Gene Name & Wt & Xpc-/- \\
\hline $\operatorname{Arl} 4^{*}$ & ADP-ribosylation factor-like 4 & 1.15 & 1.20 \\
\hline Asf1 b* & $\begin{array}{l}\text { ASF1 anti-silencing function } 1 \\
\text { homolog B }\end{array}$ & 1.24 & 1.25 \\
\hline Ccnb2 & cyclin B2 & -1.24 & -1.16 \\
\hline Cdc25c & $\begin{array}{l}\text { cell division cycle } 25 \text { homolog } \\
\text { C (S. cerevisiae) }\end{array}$ & -1.09 & -1.30 \\
\hline Cdc42ep4 & $\begin{array}{l}\text { CDC42 effector protein (Rho } \\
\text { GTPase binding) } 4\end{array}$ & 1.33 & 1.29 \\
\hline Cdca8 & cell division cycle associated 8 & -1.24 & -1.11 \\
\hline $\mathrm{Cit}^{*}$ & citron & 1.20 & 1.35 \\
\hline $\mathrm{Cks} 2^{*}$ & $\begin{array}{l}\text { CDC28 protein kinase } \\
\text { regulatory subunit } 2\end{array}$ & 1.29 & 1.36 \\
\hline Ect2* & ect2 oncogene & 1.25 & 1.45 \\
\hline Got1 & $\begin{array}{l}\text { glutamate oxaloacetate } \\
\text { transaminase } 1 \text {, soluble }\end{array}$ & 1.24 & 1.24 \\
\hline Gpsm2* & $\begin{array}{l}\text { G-protein signalling } \\
\text { modulator } 2 \text { (AGS3-like) }\end{array}$ & 1.23 & 1.33 \\
\hline Kpna2 & karyopherin (importin) alpha 2 & 1.35 & 1.30 \\
\hline Map3k6* & $\begin{array}{l}\text { mitogen-activated protein } \\
\text { kinase kinase kinase } 6\end{array}$ & 1.25 & 1.35 \\
\hline Psip ${ }^{*}$ & $\begin{array}{l}\text { PC4 and SFRS1 interacting } \\
\text { protein } 1\end{array}$ & 1.17 & 1.30 \\
\hline $\mathrm{Rrm} 1^{*}$ & ribonucleotide reductase $\mathrm{M} 1$ & 1.18 & 1.22 \\
\hline Tacc3* $^{*}$ & $\begin{array}{l}\text { transforming, acidic coiled- } \\
\text { coil containing protein } 3\end{array}$ & 1.31 & 1.34 \\
\hline Tdp1 & $\begin{array}{l}\text { tyrosyl-DNA } \\
\text { phosphodiesterase } 1\end{array}$ & 1.28 & 1.21 \\
\hline Tubd $1^{*}$ & tubulin, delta 1 & 1.26 & 1.30 \\
\hline
\end{tabular}

Gene expression ratios are presented of 18 differentially regulated genes involved in $\mathrm{G} 2$ to $\mathrm{M}$ phase transition based on microarray results. These 18 genes, of which 3 were down regulated and 15 were up regulated after B[a]P exposure, showed a trend towards a more pronounced induction in $\mathrm{Xpc}^{-1-}$ mice as compared to Wt mice $(p=0.086)$. However, a less extensive down regulation is not the same as a greater induction. Therefore, an additional $p$-value was calculated for the 15 up regulated genes, showing that 11 (indicated with *) out of these 15 up regulated

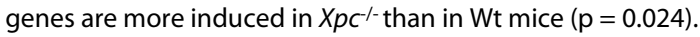

dehydrogenase (ubiquinone) subunits, cytochrome c and cytochrome c oxidase were differentially regulated (Additional file 7). Therefore, the motility and the fertilizing capacity of the sperm cells might have been affected, since mitochondria in sperm are responsible for the energy supply required to propel the flagellum [10]. A change in mitochondrial activity, which leads to less potent sperm cells, may therefore be part of the protective mechanisms against DNA damage in the testis and sperm cells. Indeed, litter sizes of female mice that were fertilized by B[a]P exposed $X_{p c^{-/}}$male mice were found to be smaller (data not shown).

$\mathrm{B}[\mathrm{a}] \mathrm{P}$ is a well known mutagen and carcinogen, and mostly studied for its capacity to form bulky DNA adducts, which are mainly repaired by NER. By changing the NER capacity in $\mathrm{Xpc}^{-/-}$mice, we expected to find additional mechanisms affected by $\mathrm{B}[\mathrm{a}] \mathrm{P}$ exposure that could possibly protect the testis and male germ cells against the formation of heritable DNA damage, as a back up for the lack of GGR/NER. However, pathways involving DNA repair (other than NER) or apoptosis were not significantly enriched among our regulated genes. Nonetheless, we did find 16 differentially regulated genes that are involved in DNA repair (GO:0006281 DNA repair) (Table 4), and at least 9 out of these 16 genes are related to repair of double strand breaks and/or homologous recombination. This suggests that exposure to $\mathrm{B}[\mathrm{a}] \mathrm{P}$ may cause double strand breaks, for instance by the collapse of the replication fork in replicating cells. Indeed, the number of $\gamma \mathrm{H} 2 \mathrm{AX}$ foci, which is a hallmark for double strand 


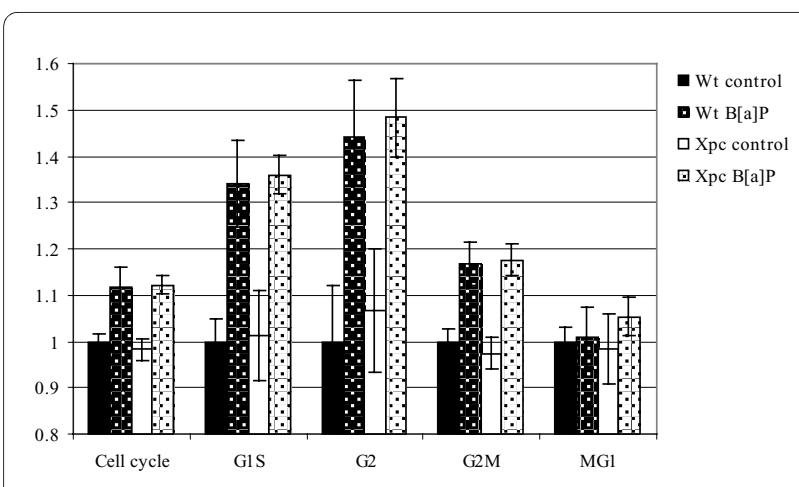

Figure 2 Average gene expression levels of cell cycle related gene sets. The setwise average expression levels of genes involved in cell cycle regulation and regulation during specific phases of the cell cycle. Error bars presented are based on the expression levels of individual mice. The average expression level of Wt control mice is set at 1.

break formation, was reported to be increased by exposure to $\mathrm{B}[\mathrm{a}] \mathrm{P}[11]$. Although the pathway involving apoptosis was not significantly enriched among our regulated genes, we found 32 apoptosis-related genes to be differentially expressed after $\mathrm{B}[\mathrm{a}] \mathrm{P}$ exposure (Table 5 ). In testes, apoptosis is a common process to discard excessive germ cells, or to remove severely damaged germ cells [12]. From our data it is hard to conclude whether apoptosis is elicited by $\mathrm{B}[\mathrm{a}] \mathrm{P}$ exposure, since we found only a small number of differentially expressed genes after $\mathrm{B}[\mathrm{a}] \mathrm{P}$ exposure and both pro-apoptotic and anti-apoptotic signals were found. For example, cytochrome c (Cycs) was up regulated after exposure in both Wt and $\mathrm{Xpc}^{-/-}$mice, which could be indicative for the initiation of the intrinsic apoptotic pathway. On the other hand, the expression of the anti-apoptotic gene Faim (Fas apoptotic inhibitory molecule) was also up regulated after $\mathrm{B}[\mathrm{a}] \mathrm{P}$ exposure, indicating an inhibitory effect on the apoptotic pathway [13]. Several aspects should be considered for the interpretation of transcriptional data regarding the regulation of apoptosis after B[a]P exposure; 1) the large number of apoptotic cells in normal testis will make it difficult to measure subtle changes in the apoptotic response after a single $\mathrm{B}[\mathrm{a}] \mathrm{P}$ exposure, 2) the apoptotic response after $\mathrm{B}[\mathrm{a}] \mathrm{P}$ exposure is an acute response that is probably hard to assess 4 days after exposure, and 3) the activation of the different caspases leading to fragmentation of DNA occurs by cleavage of procaspases already stored in the cell, a process that is unlikely to be found at the transcriptional level [14]. It should be noted that this last point may also hold true for other processes such as DNA repair, which also relies on activation and transport of already existing proteins.

To have a better understanding of the changes in cell cycle regulation, we compared setwise average expression levels of genes related to specific cell cycle phases between the 4 experimental groups. Genes involved in the G1 to S phase transition and the G2 to M phase transition were induced in animals of both genotypes after $\mathrm{B}[\mathrm{a}] \mathrm{P}$ exposure, suggesting that cells may accumulate in both G1 and G2. Cell cycle arrest after B[a]P exposure was previously found, using MCF-7 (human breast carcinoma) and HepG2 (human hepatocarcinoma) cells, and identified altered expression of genes that affect cell cycle regulation [15]. Moreover, cell cycle phases assessed by FACS analysis indeed showed an accumulation of cells in the $\mathrm{G} 1$ and $\mathrm{G} 2$ phase after $\mathrm{B}[\mathrm{a}] \mathrm{P}$ exposure [15]. It has also been shown that benzo [a]pyrene-7,8-dihydrodiol (BPD) and benzo(a)pyrene-diol-epoxide (BPDE), both metabolites of B[a]P, can induce a G2/M accumulation [16]. All these data are in line with our findings in testis of $\mathrm{B}[\mathrm{a}] \mathrm{P}$ exposed male mice.

The B[a]P induced G1-S arrest did not differ between Wt and $X_{p c}^{-1-}$ mice $(\mathrm{p}=0.937)$. However, expression of G2-M phase genes showed a trend towards a higher induction of these genes in testes of $\mathrm{Xpc}^{-/}$mice after $\mathrm{B}[\mathrm{a}] \mathrm{P}$ exposure $(\mathrm{p}=0.086)$. Therefore, the expression ratios of 4 G2-M phase genes were validated by qPCR, and results of 3 out of these 4 genes confirmed that $\mathrm{B}[\mathrm{a}] \mathrm{P}$ induces slightly higher gene expression changes in $\mathrm{Xpc}^{-/-}$ mice than in Wt mice. However, the level of induction by $\mathrm{B}[\mathrm{a}] \mathrm{P}$ exposure was higher on basis of microarray analysis, than by qPCR analysis. QPCR could not confirm the induction of $A s f 1 b$ gene expression by $\mathrm{B}[\mathrm{a}] \mathrm{P}$ as shown by microarray analysis, although the difference in gene expression ratios between Wt and $\mathrm{Xpc}^{-1-}$ mice remained small. Such a small difference in reaction may be explained by the fact that $\mathrm{Xpc}^{-/-}$mice are less capable of removing $\mathrm{B}[\mathrm{a}] \mathrm{P}$ induced damage in testis [5], and therefore more damaged cells are arrested (instead of a stronger reaction in each individual cell). This was also observed in a study using UVB irradiated Xpc-deficient epidermal cells [17]; Xpc-deficient cells were blocked in the late $\mathrm{S}$ phase due to incomplete DNA replication at sites of damaged DNA [17]. As a result, the regulation of the G2 phase genes might differ slightly between $\mathrm{Xpc}^{-/}$ and Wt mice, as found in this study.

Unrepaired DNA damage blocks the cell cycle. However, specialized Y-family DNA polymerases are capable of extending replication beyond lesions in an error-free or error-prone way [17]. For example the expression of DNA polymerase $\kappa$ (Polk) is under the control of the $\mathrm{B}[\mathrm{a}] \mathrm{P}$ activated arylhydrocarbon receptor (AhR), and more highly expressed in testes than in other tissues $[18,19]$. It bypasses BPDE- $\mathrm{N}_{2}-\mathrm{dG}$ in an efficient and mostly error-free way [19]. If we assume that DNA repair deficient $\mathrm{Xpc}^{-/-}$cells that are present in testes (such as Sertoli cells, Leydig cells and developing sperm cells), in contrast to DNA repair proficient Wt cells, are blocked in 
Table 4: Differentially regulated genes concerning DNA repair.

\begin{tabular}{|c|c|c|c|}
\hline Symbol & Gene Name & $\mathbf{W t}$ & Xpc-I- \\
\hline 5830483C08Rik & riken cDNA 5830483c08 gene & 1.13 & 1.17 \\
\hline Als4 & amyotrophic lateral sclerosis 4 homolog (human) & 1.28 & 1.44 \\
\hline Asf1a & asf1 anti-silencing function 1 homolog a (s. cerevisiae) & -1.34 & -1.24 \\
\hline $\mathrm{Brca}^{*}$ & breast cancer 2 & -1.35 & -1.34 \\
\hline Cry1 & cryptochrome 1 (photolyase-like) & 1.19 & 1.29 \\
\hline Cspg6* & chondroitin sulfate proteoglycan 6 & 1.39 & 1.40 \\
\hline Fbxo18 & f-box protein 18 & 1.13 & 1.26 \\
\hline Hmgn1 & high mobility group nucleosomal binding domain 1 & 1.36 & 1.36 \\
\hline $\mathrm{Mpg}^{*}$ & n-methylpurine-dna glycosylase & 1.38 & 1.36 \\
\hline Polg & polymerase (dna directed), gamma & 1.36 & 1.42 \\
\hline $\operatorname{Rad} 17^{*}$ & rad17 homolog (s. pombe) & 1.22 & 1.27 \\
\hline $\operatorname{Rad52*}$ & rad52 homolog (s. cerevisiae) & -1.21 & -1.16 \\
\hline Ssrp1* & structure specific recognition protein 1 & 1.13 & 1.30 \\
\hline Tdp1* & tyrosyl-dna phosphodiesterase 1 & 1.28 & 1.21 \\
\hline Xpc & xeroderma pigmentosum, complementation group $\mathrm{C}$ & -1.07 & -1.11 \\
\hline $\operatorname{Xrcc} 2^{*}$ & $\begin{array}{l}\text { x-ray repair complementing defective repair in chinese } \\
\text { hamster cells } 2\end{array}$ & -1.28 & -1.16 \\
\hline $\operatorname{Xrcc5}^{*}$ & $\begin{array}{l}\text { x-ray repair complementing defective repair in chinese } \\
\text { hamster cells } 5\end{array}$ & 1.23 & 1.35 \\
\hline
\end{tabular}

16 differentially regulated genes concerning DNA repair. Results are presented as average gene expression ratios between exposed and control samples. *genes associated with double strand breaks and/or homologous recombination

the late $\mathrm{S}$ phase due to unrepaired damage, then this damage could be passed in an error-free way with progression of the cell cycle and spermatogenesis, but without the actual removal of the blocking lesion. Although Polk was not present among the differentially expressed genes by using Two-Way ANOVA, we found, however, that the expression of Pol $\kappa$ was significantly higher in

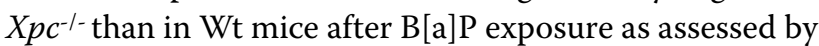
a simple $\mathrm{T}$-test $(\mathrm{p}=0.038)$. However, this differential expression between $\mathrm{Wt}$ and $\mathrm{Xpc}^{-/}$- mice after $\mathrm{B}[\mathrm{a}] \mathrm{P}$ exposure was found only after correction for the slight initial expression differences found in their unexposed counterparts. Progression of the cell cycle and spermatogenesis, without the actual removal of the DNA lesion is in line with the differences in DNA damage kinetics between $\mathrm{Xpc}^{-1-}$ and Wt mice found in our previous study [5]. Therefore, we suggest that $X p c^{-/}$mice are not per se more sensitive to mutation induction in the testis than Wt mice after $\mathrm{B}[\mathrm{a}] \mathrm{P}$ exposure, and thereby could have equal risks for heritable gene mutations. However, future studies analyzing mutation induction should elucidate the mutagenic potency of $\mathrm{B}[\mathrm{a}] \mathrm{P}$ in this reproductive organ.

\section{Conclusion}

From this study, we can conclude that gene expression in testis of untreated $\mathrm{Xpc}^{-/-}$and Wt mice are similar, and this is also the case after exposure to $\mathrm{B}[\mathrm{a}] \mathrm{P}$. $\mathrm{B}[\mathrm{a}] \mathrm{P}$ exposure, which formed a substantial amount of DNA damage, differentially regulated 984 genes that were enriched for cell cycle, translation, chromatin structure and spermatogenesis. Overall, B[a]P-induced gene expression changes in $\mathrm{Xpc}^{-1-}$ mice differed from their exposed wild type counterparts $(\mathrm{p}=0.000000141)$, which was also found for stage specific cell cycle gene sets. These gene expression changes in testis may represent a cell cycle block due to the presence of unrepaired damage. Specialized DNA polymerases that are highly expressed in testis may still bypass $\mathrm{B}[\mathrm{a}] \mathrm{P}$ induced DNA damage in an error-free way, and cell cycle/spermatogenesis can thus progress in the presence of DNA lesions.

\section{Methods}

\section{Animal experiments}

Male wild type (C57BL/6) and $\mathrm{Xpc}^{-1-}$ mice $(\mathrm{C} 57 \mathrm{BL} / 6)$, as previously described $[9,20]$, were exposed to a single dose of $\mathrm{B}[\mathrm{a}] \mathrm{P}(13 \mathrm{mg} / \mathrm{kg} \mathrm{bw})$ by oral gavage, and were sacrificed 4 days after exposure. All groups consisted of 5 mice. The dose of $13 \mathrm{mg} / \mathrm{kg}$ bw has been used in previous studies and is appropriate to induce detectable DNA adduct levels [21]. The control groups received the solvent sunflower oil and were also sacrificed at day 4 after exposure. Testes were snap frozen in liquid nitrogen and 
Table 5: Differentially regulated genes concerning apoptosis.

\begin{tabular}{|c|c|c|c|}
\hline Symbol & Gene Name & $\mathbf{W t}$ & Xpc-I- \\
\hline 1700003F12Rik & riken cdna $1700003 f 12$ gene & 1.44 & 1.45 \\
\hline Atp7a & $\begin{array}{l}\text { atpase, } \mathrm{cu}++ \text { transporting, alpha } \\
\text { polypeptide }\end{array}$ & 1.15 & 1.29 \\
\hline Bag1 & bcl2-associated athanogene 1 & 1.49 & 1.42 \\
\hline Bag4 & bcl2-associated athanogene 4 & -1.26 & -1.25 \\
\hline Brca2 & breast cancer 2 & -1.35 & -1.34 \\
\hline Cycs & cytochrome c, somatic & 1.21 & 1.37 \\
\hline Dap & death-associated protein & 1.31 & 1.25 \\
\hline Dhcr24 & 24-dehydrocholesterol reductase & 1.50 & 1.43 \\
\hline Dpf2 & $\mathrm{d} 4$, zinc and double phd fingers family 2 & 1.31 & 1.17 \\
\hline Faim & fas apoptotic inhibitory molecule & 1.21 & 1.20 \\
\hline Hells & helicase, lymphoid specific & 1.43 & 1.46 \\
\hline Hras1 & harvey rat sarcoma virus oncogene 1 & 1.20 & 1.15 \\
\hline Klrb1c & $\begin{array}{l}\text { killer cell lectin-like receptor subfamily b } \\
\text { member } 1 c\end{array}$ & -1.09 & -1.18 \\
\hline Opa1 & optic atrophy 1 homolog (human) & -1.34 & -1.17 \\
\hline $\mathrm{P} 2 \mathrm{rx} 1$ & $\begin{array}{l}\text { purinergic receptor p2x, ligand-gated } \\
\text { ion channel, } 1\end{array}$ & 1.10 & 1.17 \\
\hline Pdcd5 & programmed cell death 5 & -1.22 & -1.23 \\
\hline Pim1 & proviral integration site 1 & -1.17 & -1.17 \\
\hline Proc & protein c & 1.26 & 1.22 \\
\hline Pten & phosphatase and tensin homolog & 1.32 & 1.31 \\
\hline Purb & purine rich element binding protein $b$ & 1.16 & 1.30 \\
\hline Qars & glutaminyl-trna synthetase & 1.20 & 1.35 \\
\hline Rragc & ras-related gtp binding $c$ & 1.29 & 1.25 \\
\hline Rybp & ring 1 and yy 1 binding protein & 1.18 & 1.37 \\
\hline Sh3 kbp1 & sh3-domain kinase binding protein 1 & -1.37 & -1.39 \\
\hline Smndc1 & $\begin{array}{l}\text { survival motor neuron domain } \\
\text { containing } 1\end{array}$ & 1.21 & 1.35 \\
\hline Sra1 & steroid receptor rna activator 1 & 1.26 & 1.23 \\
\hline Sycp3 & synaptonemal complex protein 3 & 1.34 & 1.30 \\
\hline Tax1 bp1 & $\begin{array}{l}\text { tax } 1 \text { (human } \mathrm{t} \text {-cell leukemia virus type i) } \\
\text { binding protein } 1\end{array}$ & 1.25 & 1.08 \\
\hline Tnfrsf4 & $\begin{array}{l}\text { tumor necrosis factor receptor } \\
\text { superfamily, member } 4\end{array}$ & 1.30 & 1.11 \\
\hline Uaca & $\begin{array}{l}\text { uveal autoantigen with coiled-coil } \\
\text { domains and ankyrin repeats }\end{array}$ & 1.24 & 1.29 \\
\hline Uaca & $\begin{array}{l}\text { uveal autoantigen with coiled-coil } \\
\text { domains and ankyrin repeats }\end{array}$ & 1.14 & 1.21 \\
\hline Zdhhc16 & zinc finger, dhhc domain containing 16 & 1.25 & 1.36 \\
\hline
\end{tabular}

32 differentially regulated genes concerning apoptosis. Results are presented as average gene expression ratios between exposed and control samples. 
stored at $-80^{\circ} \mathrm{C}$ until analysis. Mice were bred and housed under specific pathogen-free conditions in a 12-hour light-dark cycle at the animal facilities of the Netherlands Vaccine Institute (NVI, Bilthoven, the Netherlands), and received food and water ad libitum. Experiments were approved by the NVI's Animal Ethics Committee and were carried out according to their guidelines.

\section{RNA isolation and purification}

After testes had been pulverized using mortar and tamper cooled in liquid nitrogen, TRIzol ${ }^{\circ}$ Reagent (Invitrogen, Breda, the Netherlands) was added to the material and RNA was isolated using an RNeasy Mini Kit (Qiagen, Venlo, the Netherlands) with DNase treatment according to the manufacturer's protocol with minor modifications. RNA quantity was determined spectrophotometrically and RNA purity was assessed on an Agilent 2100 Bioanalyzer (Agilent Technologies, Amstelveen, the Netherlands). All samples were pure and free of RNA degradation.

\section{RNA labelling and hybridization on microarrays}

Cyanine labelled cRNA was generated by using the TwoColor Microarray-Based Gene Expression Analysis kit from Agilent Technologies according to the manufacturer's protocol. All samples were labelled with Cy5, and 3 samples of unexposed Wt mice were labelled with Cy3, pooled and used as a reference sample.

On the basis of dye incorporation rates, appropriate amounts of Cy5 and Cy3 labelled samples (10 pmol each) were simultaneously hybridized on Agilent 22K Mouse microarrays (Agilent Technologies). After hybridization, slides were washed and dried with $\mathrm{N}_{2}$ gas before scanning.

\section{Image analysis}

Slides were scanned on a GenePix 4000B Microarray Scanner (Molecular Devices, Sunnyvale, CA, USA). Cy5 and Cy3 were excited at wavelengths of 635 and $532 \mathrm{~nm}$, respectively. Laser power was set to $100 \%$. The photo multiplier was set to a saturation tolerance of $0.02 \%$ to minimize background and saturated spots. The images obtained (resolution 5 micron, 16 bit tiff images) were processed with Imagene 8.0.1 software (Biodiscovery, El Segundo, CA, USA) to measure mean signal intensities for spots and local backgrounds.

\section{Quality control}

Quality control was performed on raw data by means of a scatter plot and MA-plot as well as a normal probability plot to assess signal distribution. Positive (landmark) and negative (blank) spots were used for quality control but not included in further analyses. Microarray spot signal data were normalized in $\mathrm{R}$ using a four-step approach of (1) natural log-transformation, (2) quantile normalization of all scans, (3) correction of the sample spot signal for the corresponding reference spot signal and (4) averaging data from replicate spots. Normalized data were visualized by Principal Component Analysis (PCA) for additional quality control. The gene expression data discussed in this publication have been deposited in NCBI's Gene Expression Omnibus [22] and are accessible through GEO Series accession number GSE17979 http:// www.ncbi.nlm.nih.gov/geo/query/ acc.cgi? acc $=$ GSE17979.

\section{Data analysis}

Significance of differences in gene expression between genotype and/or treatment groups was calculated by a Two-Way ANOVA, where genes with a false discovery rate (FDR) below 5\% were selected as differentially expressed. Differentially expressed genes were clustered (based on Euclidian Distance and Ward linkage) using GeneMaths (Applied Maths, St-Martens-Latem, Belgium). By using the DAVID/EASE http:// david.abcc.ncifcrf.gov web application, functional annotation and Gene Ontology (GO) term enrichment were determined for three different gene sets, namely $\mathrm{B}[\mathrm{a}] \mathrm{P}$ induced genes, $\mathrm{B}[\mathrm{a}] \mathrm{P}$ suppressed genes and all regulated genes together $(\mathrm{FDR}<0.1)[23,24]$.

Pathway enrichment among $\mathrm{B}[\mathrm{a}] \mathrm{P}$ regulated genes was further used to identify regulated genes within a pathway, and to compare the average gene expression ratios of $\mathrm{B}[\mathrm{a}] \mathrm{P}$ treated $v s$. control groups between the two genotypes. Pathways with related terms for cell cycle, translation, chromatin structure and spermatogenesis, which were already found to be enriched among the up regulated genes, were combined to form 4 groups of genes that were used for this comparison.

For visualization of cell cycle phase activity, the average gene expression for suitable gene sets was calculated. Sets used were based on either GO functional annotation or on genes found specifically expressed in a particular cell cycle phase by both Bar-Joseph et al. [7] and Whitfield et al. [8], but only used for calculation if they contained at least 4 genes. Setwise average gene expression levels for each experimental group were expressed relative to the Wt control mice, for which the level was set at 1 .

\section{Quantitative Real-Time PCR}

For qPCR of 4 selected genes (ASf1b, Cit, Ect2 and Psip1) and reference gene Hprt1, cDNA was synthesized using the iScript cDNA Synthesis kit (Bio-Rad, Veenendaal, the Netherlands) according to the manufacturer's protocol, starting with $0.5 \mu \mathrm{g}$ of RNA. QPCR was performed on a MyiQ $^{\mathrm{m}}$ Single-Color Real-Time PCR detection system (Biorad) using the $\mathrm{iQ}^{\mathrm{TM}} \mathrm{SYBR}^{\circ}$ Green Supermix (Bio-Rad) according to the manufacturer's protocol with minor modifications, $5 \mu \mathrm{l}$ of 10 times diluted cDNA and $0.3 \mu \mathrm{M}$ 
primers in a total volume of $25 \mu \mathrm{l}$. Samples were amplified under the following conditions: $95^{\circ} \mathrm{C}$ for 3 minutes, followed by 40 cycles at $95^{\circ} \mathrm{C}$ for 15 seconds and $60^{\circ} \mathrm{C}$ for 45 seconds. PCR was checked for a-specific products by performing a melting curve analysis $\left(65^{\circ} \mathrm{C}-95^{\circ} \mathrm{C}\right)$. Data were analyzed using the $\mathrm{MyiQ}^{\mathrm{m}}$ Software system (BioRad) and were expressed as average gene expression ratios as compared to controls.

\section{Additional material}

Additional file 1 Processes enriched among B[a]P induced genes. The data presented are terms enriched among the $\mathrm{B}[\mathrm{a}] \mathrm{P}$ induced gene list by DAVID/EASE with an FDR $<0.1$.

Additional file 2 Processes enriched among B[a]P suppressed genes The data presented are terms enriched among the B[a]P suppressed gene list by DAVID/EASE with an FDR $<0.1$.

Additional file 3 Processes affected by $\mathrm{B}$ [a]P exposure in mouse testis The data presented are terms enriched among the B[a]P modulated gene list by DAVID/EASE with an FDR $<0.1$.

Additional file 4 Differentially regulated genes after $\mathrm{B}[\mathrm{a}] \mathrm{P}$ exposure involved in Chromatin structure. 37 differentially regulated genes involved in Chromatin structure. Results are presented as average gene expression ratios between exposed and control samples.

Additional file 5 Differentially regulated genes after $\mathrm{B}[\mathrm{a}] \mathrm{P}$ exposure regulating Spermatogenesis. 32 differentially regulated genes involved in Spermatogenesis. Results are presented as average gene expression ratios between exposed and control samples.

Additional file 6 Differentially regulated genes after B[a]P exposure involved in Translation. 59 differentially regulated genes involved in Translation. Results are presented as average gene expression ratios between exposed and control samples.

Additional file 7 Differentially regulated genes after $\mathrm{B}[\mathrm{a}] \mathrm{P}$ exposure involved in Mitochondrial function. 51 differentially regulated genes involved in mitochondrial function. Results are presented as average gene expression ratios between exposed and control samples. * ${ }^{*}$ enes involved in oxidative phosphorylation.

\section{Authors' contributions}

NV carried out the RNA isolation, the labelling and hybridization of the samples and the image analyses, and wrote the manuscript. JP carried out the data and statistical analyses, and has been involved in writing the manuscript. CO carried out the animal experiments. JB, FS and HS participated in the design of the study, interpretation of the data and revision of the manuscript. RG conceived the design of the study, participated in the interpretation of the data, and helped to draft the manuscript. All authors read and approved the final manuscript.

\section{Acknowledgements}

The authors thank E.C. Friedberg for providing the Xpc/-mice, the animal technicians of the animal facilities of the Netherlands Vaccine Institute (NVI, Bilthoven, the Netherlands) for their skilful assistance during this study, Marcel van Herwijnen and Ralph Gottschalk for their help with the microarray experiments, and Daniëlle Pachen for carrying out the Real-Time PCR experiments. This study was partly funded by the Cefic Long-range Research Initiative's (LRI) Innovative Science award 2004, and the European Network of Excellence (NoE) "Environmental cancer, nutrition and individual susceptibility" (ECNIS), sixth Framework Programme (FP6), FOOD-CT-2005-513943.

\section{Author Details}

'Department of Health Risk Analysis and Toxicology, School for Nutrition, Toxicology and Metabolism, Maastricht University, PO box 616, 6200 MD Maastricht, the Netherlands and 2Laboratory for Health Protection Research, National Institute for Public Health and the Environment (RIVM), PO box 1, 3720 BA Bilthoven, the Netherlands
Received: 18 September 2009 Accepted: 26 May 2010

Published: 26 May 2010

\section{References}

1. Denissenko MF, Pao A, Tang M, Pfeifer GP: Preferential formation of benzo[a]pyrene adducts at lung cancer mutational hotspots in P53. Science 1996, 274:430-432.

2. Somers $C M$, Yauk $C L$, White $P A$, Parfett $C L$, Quinn JS: Air pollution induces heritable DNA mutations. Proc Natl Acad Sci USA 2002, 99:15904-15907.

3. Vilarino-Guell C, Smith AG, Dubrova YE: Germline mutation induction at mouse repeat DNA loci by chemical mutagens. Mutat Res 2003, 526:63-73.

4. Zenzes MT, Bielecki R, Reed TE: Detection of benzo(a)pyrene diol epoxide-DNA adducts in sperm of men exposed to cigarette smoke. Fertil Steril 1999, 72:330-335.

5. Verhofstad N, van Oostrom CT, van Benthem J, van Schooten FJ, van Steeg $\mathrm{H}$, Godschalk RW: DNA adduct kinetics in reproductive tissues of DNA repair proficient and deficient male mice after oral exposure to benzo(a)pyrene. Environ Mol Mutagen 2009, 51(2):123-9.

6. Gillet LC, Scharer OD: Molecular mechanisms of mammalian global genome nucleotide excision repair. Chem Rev 2006, 106:253-276.

7. Bar-Joseph Z, Siegfried Z, Brandeis M, Brors B, Lu Y, Eils R, Dynlacht BD, Simon I: Genome-wide transcriptional analysis of the human cell cycle identifies genes differentially regulated in normal and cancer cells. Proc Natl Acad Sci USA 2008, 105:955-960.

8. Whitfield ML, Sherlock G, Saldanha AJ, Murray JI, Ball CA, Alexander KE, Matese JC, Perou CM, Hurt MM, Brown PO, Botstein D: Identification of genes periodically expressed in the human cell cycle and their expression in tumors. Mol Biol Cell 2002, 13:1977-2000.

9. Cheo DL, Ruven HJ, Meira LB, Hammer RE, Burns DK, Tappe NJ, van Zeeland AA, Mullenders LH, Friedberg EC: Characterization of defective nucleotide excision repair in XPC mutant mice. Mutat Res 1997, 374:1-9.

10. Kao SH, Chao HT, Wei YH: Multiple deletions of mitochondrial DNA are associated with the decline of motility and fertility of human spermatozoa. Mol Hum Reprod 1998, 4:657-666.

11. Zhou C, Li Z, Diao H, Yu Y, Zhu W, Dai Y, Chen FF, Yang J: DNA damage evaluated by gammaH2AX foci formation by a selective group of chemical/physical stressors. Mutat Res 2006, 604:8-18.

12. Tripathi R, Mishra DP, Shaha C: Male germ cell development: turning on the apoptotic pathways. Journal of reproductive immunology 2009, 83:31-35.

13. Huo J, Xu S, Guo K, Zeng Q, Lam KP: Genetic deletion of faim reveals its role in modulating c-FLIP expression during CD95-mediated apoptosis of lymphocytes and hepatocytes. Cell death and differentiation 2009, 16:1062-1070

14. Boatright KM, Salvesen GS: Mechanisms of caspase activation. Current opinion in cell biology 2003, 15:725-731

15. Hockley SL, Arlt VM, Brewer D, Giddings I, Phillips DH: Time- and concentration-dependent changes in gene expression induced by benzo(a)pyrene in two human cell lines, MCF-7 and HepG2. BMC Genomics 2006, 7:260.

16. Caino MC, Oliva JL, Jiang H, Penning TM, Kazanietz MG: Benzo[a]pyrene7,8-dihydrodiol promotes checkpoint activation and G2/M arrest in human bronchoalveolar carcinoma H358 cells. Mol Pharmacol 2007, 71:744-750

17. van Oosten M, Stout GJ, Backendorf C, Rebel H, de Wind N, Darroudi F, van Kranen HJ, de Gruijl FR, Mullenders LH: Mismatch repair protein Msh2 contributes to UVB-induced cell cycle arrest in epidermal and cultured mouse keratinocytes. DNA Repair (Amst) 2005, 4:81-89.

18. Gerlach VL, Aravind L, Gotway G, Schultz RA, Koonin EV, Friedberg EC: Human and mouse homologs of Escherichia coli DinB (DNA polymerase IV), members of the UmuC/DinB superfamily. Proc Nat Acad SciUSA 1999, 96:11922-11927.

19. Ogi T, Mimura J, Hikida M, Fujimoto H, Fujii-Kuriyama $Y$, Ohmori $\mathrm{H}$ : Expression of human and mouse genes encoding polkappa: testisspecific developmental regulation and AhR-dependent inducible transcription. Genes Cells 2001, 6:943-953.

20. Hoogervorst EM, van Oostrom CT, Beems RB, van Benthem J, Berg J van den, van Kreijl CF, Vos JG, de Vries A, van Steeg H: 2-AAF-induced tumor development in nucleotide excision repair-deficient mice is associated with a defect in global genome repair but not with transcription coupled repair. DNA Repair (Amst) 2005, 4:3-9. 
21. de Vries A, Dolle ME, Broekhof JL, Muller JJ, Kroese ED, van Kreijl CF, Capel PJ, Vijg J, van Steeg H: Induction of DNA adducts and mutations in spleen, liver and lung of XPA-deficient/lacZ transgenic mice after oral treatment with benzo[a]pyrene: correlation with tumour development. Carcinogenesis 1997, 18:2327-2332.

22. Edgar R, Domrachev M, Lash AE: Gene Expression Omnibus: NCBI gene expression and hybridization array data repository. Nucleic Acids Res 2002, 30:207-210.

23. Dennis G Jr, Sherman BT, Hosack DA, Yang J, Gao W, Lane HC, Lempicki RA: DAVID: Database for Annotation, Visualization, and Integrated Discovery. Genome Biol 2003, 4:P3.

24. Huang DW, Sherman BT, Lempicki RA: Systematic and integrative analysis of large gene lists using DAVID bioinformatics resources. Nature protocols 2009, 4:44-57.

doi: 10.1186/1471-2164-11-333

Cite this article as: Verhofstad et al., Benzo(a)pyrene induces similar gene expression changes in testis of DNA repair proficient and deficient mice BMC Genomics 2010, 11:333

Submit your next manuscript to BioMed Central and take full advantage of:

- Convenient online submission

- Thorough peer review

- No space constraints or color figure charges

- Immediate publication on acceptance

- Inclusion in PubMed, CAS, Scopus and Google Scholar

- Research which is freely available for redistribution

Submit your manuscript at www.biomedcentral.com/submit 